This item was submitted to Loughborough's Research Repository by the author.

Items in Figshare are protected by copyright, with all rights reserved, unless otherwise indicated.

\title{
Making sense of business analytics in project selection and prioritisation: Insights from the start-up trenches
}

PLEASE CITE THE PUBLISHED VERSION

https://doi.org/10.1108/ITP-09-2020-0633

PUBLISHER

Emerald

VERSION

AM (Accepted Manuscript)

\section{PUBLISHER STATEMENT}

This paper was accepted for publication in the journal Information Technology and People and the definitive published version is available at https://doi.org/10.1108/ITP-09-2020-0633

LICENCE

CC BY-NC-ND 4.0

\section{REPOSITORY RECORD}

Zamani, Efpraxia D, Anastasia Griva, Konstantina Spanaki, Paidi O’Raghallaigh, and David Sammon. 2021. "Making Sense of Business Analytics in Project Selection and Prioritisation: Insights from the Start-up Trenches". Loughborough University. https://hdl.handle.net/2134/14377280.v1. 


\section{eEmerald $\begin{aligned} & \text { Information Technology } \\ & \text { \& People }\end{aligned}$}

\section{Making Sense Of Business Analytics In Project Selection And Prioritisation: Insights From The Start-Up Trenches}

\begin{tabular}{|r|l|}
\hline Journal: & Information Technology \& People \\
\hline Manuscript ID & ITP-09-2020-0633.R2 \\
\hline Manuscript Type: & Article \\
\hline Keywords: & $\begin{array}{l}\text { Global software development < Information system development < } \\
\text { Practice, Sensemaking < Phenomenon, IT project management }< \\
\text { Information system development < Practice, Case study < Methodology, } \\
\text { Business Intelligence < Management practices < Practice, Grounded } \\
\text { theory < Methodology }\end{array}$ \\
\hline \multicolumn{2}{|l}{} \\
\hline
\end{tabular}

\section{SCHOLARONE \\ Manuscripts}




\title{
Making Sense Of Business Analytics In Project Selection And Prioritisation: Insights From The Start-Up Trenches
}

\begin{abstract}
Purpose: The study aims to provide insight in the sensemaking process and the use of business analytics (BA) for project selection and prioritisation in start-up settings. A major focus is on the various ways start-ups can understand their data through the analytical process of sensemaking.

Research Methods: This is a comparative case study of two start-ups that use BA in their projects. We follow an interpretive approach and draw from the constructivist Grounded Theory Method (GTM) approach for the purpose of data analysis, whereby the theory of Sensemaking functions as the sensitising device that supports us in the interpretation of our data.

Findings: The key findings lie within the scope of project selection and prioritisation, where the sensemaking process is implicitly influenced by each start-up's strategy and business model. BA help start-ups notice changes within their internal and external environment and focus their attention on the more critical questions along the lines of their processes, operations and business model. However, BA alone cannot support decision-making around less structured problems such as project selection and prioritisation, where intuitive judgement and personal opinion are still heavily used.

Originality/value: Our study extends the research on business analytics (BA) applied in organisations as tools for business development. Specifically, we draw on the literature of BA tools in support of project management from multiple perspectives. The perspectives include but are not limited to project assessment and prioritisation. We view the decision-making process and the path from insight to value, as a sensemaking process, where data become part of the sensemaking roadmap and BA help start-ups navigate the decision-making process.
\end{abstract}

Keywords: business analytics, software development, sensemaking, start-up, project prioritisation, project selection 


\section{Introduction}

Business analytics (BA) have been evolving rapidly, fostering significant change in a number of areas: from operations, manufacturing and large organisations (e.g., Gunasekaran et al., 2018) to retail, marketing (e.g., Griva et al., 2018, 2021), gaming (Mäntymäki et al., 2020b) and start-ups to name only a few. The increasing interest stems largely from the potential, and the view organisations hold for BA; some see BA as the next frontier for innovation, competition, and productivity (Manyika et al., 2011), supporting decision making and understanding (Mäntymäki et al., 2020b), while others go even a step further suggesting that BA have the potential to transform the way we live, work, and think (MayerSchönberger \& Cukier, 2013). Applying BA in organisational and operational processes and activities can lead to new insights and improved business outcomes (Gartner, 2018), and support evidencebased decision-making (Pappas et al., 2018). BA insights can result in improving both marketing and technological capabilities, two of the core pillars of competitive performance (Mikalef et al., 2020).

Despite the promise of BA for enhanced business outcomes, recent findings suggest that there is a fragmented understanding around their role (Conboy, Dennehy, et al., 2020) and the exact way these tools create and extract value from the data for business decisions (Dong \& Yang, 2020). Businesses need to use BA in a way that allows them to move from data to explicit insights, to decision-making (Sharma et al., 2014). However, oftentimes, they are faced with unstructured problems, where BA alone cannot lead to a straightforward decision. Such unstructured problems may range from project selection and prioritisation to new product development (Pun et al., 2010), where decisions influence and are being influenced by higher-level dimensions, such as strategy and long term goals, which cannot be easily captured by BA. Therefore, in such instances, BA must be combined with "superior decision-making" to create value (Sharma et al., 2014, p. 433), where intuitive judgement seems to be still relevant and warranted (Constantiou et al., 2019).

We focus specifically on the use of BA for unstructured problems, namely project selection and prioritisation, with the aim to understand how BA support businesses with pivotal decision-making. Our specific research question is "How do start-ups leverage business analytics to select and prioritise their projects?" To address this, we apply a sensemaking lens and posit that the theory of Sensemaking (Weick et al., 2005; Weick \& Sutcliffe, 2015) can help us understand how businesses make sense of their data (Namvar \& Cybulski, 2014) against the background of external and internal events when decisions are critical for the trajectory of the business (Meskendahl, 2010). On the one hand, sensemaking allows us to theoretically frame and inductively theorise about the use of BA for decision making. On the other hand, sensemaking as a theoretical lens allows us to place the emphasis not solely on the decision being made at the end of the process, but also on the process itself, i.e., the actions that precede the decisions (Glynn \& Watkiss, 2020; Weick et al., 2005). This is of extreme relevance for the field of $B A$, where presently research is focused on exploring the range of insights businesses may receive from $B A$, how exactly they may act upon these, and what potentially may be the actions that link insights and decisions (Seddon et al., 2017). We thus posit that focusing on how businesses enact their BA-enabled sensemaking will offer us the opportunity to address these important questions and draw interesting insights and lessons learned.

We position our study specifically within the context of start-ups: increasingly, start-ups move to datadriven business models, whereby BA constitute a core part of their activities (Hilbig et al., 2018); and start-ups are required to use cutting edge techniques and methods to achieve and maintain their competitive advantage (Behl et al., 2019).

The next section provides an overview of the literature on BA and a discussion of sensemaking theory that guides our research. Next, we present our study's methods, and we then move on to presenting our findings. The paper closes with a discussion of the theoretical and practical implications of our study. 


\section{Theoretical Background}

\subsection{Overview of Business Analytics in Project Management}

An abundance of definitions and descriptions of BA exist in the literature. Mikalef et al. (2018) and Holsapple et al. (2014) have separately compiled comprehensive lists of definitions. Drawing from both studies, BA is generally seen as a collection of technologies, methodologies, systems, applications and tools that enable organisations to analyse and explore business data towards generating insights for more effective decision making.

In Project Management, BA enables teams to exploit their data and lead to self-improvement (Augustine et al., 2018). For Information Systems projects in particular, the aim of BA is specifically to extract actionable insights and aid practitioners, such as testers, project managers and developers to effectively complete development-related tasks (Zhang et al., 2013). Within the context of systems and software development and management, BA often takes the form of software metrics, to measure lead time, cycle time, throughput rate (Conboy, Dennehy, et al., 2020; Griva et al., 2020). Using analytics, project managers can calculate these metrics and answer important questions related to their projects (Augustine et al., 2018). They can make estimations on the basis of effort, velocity and releases, among other metrics (Arar \& Ayan, 2016). Their ability to extract insights can be further enhanced through the use of visual analytics (Reddivari et al., 2014).

Within the Project Management spectrum, BA can support prioritisation and selection problems in organisations. The project prioritisation and selection are usually addressed as broad portfolio management decisions (Chen et al., 2012; Holsapple et al., 2014). In the IT project prioritisation and selection literature, BA-enabled project portfolio decisions fall into the areas of optimisation and the calculation or prediction of the risk in the prioritisation and selection process (Shollo et al., 2015). BAenabled project portfolio decision-making focuses on the organisational consideration and coordination of the selection and prioritisation for each project based on the decisions of the various stakeholders (Constantiou et al., 2016; Constantiou \& Kallinikos, 2015). Shollo et al. (2015) explains also using BA insights, projects can become comparable and therefore their prioritisation can be easier. The contribution of BA in Project Management and specifically, selection and prioritisation tasks could be great, particularly when focusing on how stakeholders make sense of the insights gathered from such tools. In project selection and prioritisation, the importance of the intangible characteristics of a project and its associated assets is often neglected (Shollo et al., 2015). However, how stakeholders make sense on the basis of BA is deemed crucial for projects because value cannot always be captured through conventional methods such as cost-benefit analyses, which may result in many intangible benefits not being realised (Constantiou et al., 2016; Constantiou \& Kallinikos, 2015).

In this study, we view BA as a tool that can help project managers understand their existing and future projects better. First, BA can be used as a way for tracking, monitoring and managing the progress of a project (Conboy, Dennehy, et al., 2020). Second, Sharma et al. (2014) have argued that BA can be used for resource allocation and orchestration to help businesses reconfigure their IT capabilities (Daniel et al., 2014). On this basis, we posit that BA can be used for project portfolio management, too, as businesses leverage BA to identify areas for improvement through future projects. However, there is evidence to suggest that for this purpose, BA need to be complemented with insights from expert opinion so that reasoning and justification can be more appealing and make more sense to relevant decision makers (Constantiou et al., 2019). To understand this process, we look into the theory of sensemaking. 


\subsection{Making Sense of and with Business Analytics}

Sensemaking is triggered typically during unfamiliar or uncertain situations (Klein et al., 2007) when there is insufficient or inconsistent information in the environment (Dervin, 2003) and largely during problematic and unexpected events (Weick et al., 2005). There are different approaches to sensemaking. The first approach is that of Weick, who introduced the concept of sensemaking as organising (Weick et al., 2005). He presents sensemaking as a process where individuals extract and label parts of their experiences and then piece them together, in a way that helps them organise (Weick et al., 2005). For Dervin (2003) sensemaking supports seeking, processing, creating, and using information. Like Weick, Dervin sees sensemaking as a process, however for her "sense is the product of this process" (Savolainen, 1993, p. 16), whereas for Weick "[a]ctions are seen as the product of sensemaking" (Mesgari \& Okoli, 2019, p. 217), while sensemaking gets enacted. The macro cognitive approach to sensemaking is put forth by Klein et al. (2007). This is better known as the Data/Frame theory of sensemaking. 'Data' denotes the information available within a given context, and 'frames' denote mental representations or possible hypotheses that link the data together (Klein et al., 2007). The Data/Frame differs from Weick's approach in that it places greater emphasis on the anomaly that triggers sensemaking, the response to the anomaly, and the ripple effects of this response (Malakis \& Kontogiannis, 2013).

In this study, we adopt the approach espoused by Weick for the following reasons. It allows us to account for the organisational context, where multiple stakeholders exist and often collide, and to explore how individuals as a collective make sense of fragmented and often conflicting information (Weick et al., 2005), which is typical for project selection and prioritisation (Rodrigues et al., 2020). It also accounts for how teams interpret and overcome contradictions, inconsistencies and inefficiencies with the use of IT artefacts (Mesgari \& Okoli, 2019), such as BA in this case, to enact their newly acquired sense (Zamani et al., 2019) and make their everyday practices and decision making more orderly. Last but not least, Weick's approach allows us to pay attention on the actions that precede decision-making (Glynn \& Watkiss, 2020); as the sensemaker moves closer to a decision, there are fewer and fewer decisions left, because the sensemaker purposefully rejects some or excludes others through their own past actions (Weick \& Sutcliffe, 2015). It is these actions that we wish to explore and which we believe can elucidate how an entity like a start-up practically uses BA in order to move from BA insights to the result of making a decision.

According to Weick, sensemaking begins with noticing and bracketing, which draw from prior experiences and one's expertise and relate to potential antecedents and consequences of what is being observed (Weick et al., 2005). In this sense, noticing and bracketing support the sensemaker with simplifying what is being observed and with developing plausible stories for explaining it (Seidel et al., 2017). The next stage is that of labelling and categorising. At this stage, individuals begin abstracting from perceptually-based knowing to categorically-based knowing, in order to disregard any differences that prohibit them from finding common ground (Weick et al., 2005). Once common ground has been achieved, the next step is to identify what will be the immediate action, by assessing and reviewing the different plausible outcomes (Seidel et al., 2017).

Positioning the above discussion within the broader discourse of BA, sensemaking is "social and systemic" (Weick et al., 2005, p. 412), and thus influences and is influenced by an number of social and organisational factors (Giannakis et al., 2020). We see sensemaking as a social, organisation-wide process whereby individuals collectively embark upon the interpretation of the insights received from the $\mathrm{BA}$ in order to manage and evaluate existing and future projects, with the aim to decide on corrective actions and future implementations. Adding BA into the mix, we posit that BA is used to support decision making, i.e., action, which, nevertheless, requires somewhat more than what BA can offer: it requires contextual information that needs to be coupled with the BA output, and these together need to be interpreted and made sense of against the backdrop of the problematic situation 
that needs to be tackled (Conboy, Mikalef, et al., 2020; Constantiou et al., 2019; Fosso Wamba et al., 2015; Mikalef et al., 2020). We thus propose that BA can support:

- Noticing and bracketing, by pulling together critical information that could pass otherwise unnoticed. This way, BA, via their quantitative nature, and, often, their visual format, can help businesses simplify what is happening while offering a pathway for businesses to contextualise the insights they receive; and

- Labelling and categorising, because they allow specifying what is happening, by focusing the attention of the sensemakers around the most critical dimensions. This can be beneficial for e.g., project selection, because specifying further may entail, e.g., categorising projects based on their relative importance (Tavana et al., 2013), such as 'critical', 'important', 'strategic' etc.

Such an approach offers many possibilities:

- BA can be used for making sense of the data and the operations and proceed with decision making.

- Combined with intuitive judgement and prior experiences, BA can be used for:

- evaluating alternative scenarios and action possibilities;

- fine-tuning the design of BA tools themselves based on tangible results (feedback loop).

\section{Methodology}

Our study aims to explore and understand how BA supports the decision-making processes of startups towards project selection and prioritisation. We do this through a comparative case study of two start-ups, which allows us to answer:

"How do start-ups leverage business analytics to select and prioritise their projects?".

These two start-ups, named RetailAnalytics (case A) and SocialAnalytics (case B), were purposefully chosen over more well-established companies for a few reasons:

- BA cuts across their operations, and

- they use BA to gain and sustain their competitive advantage against well-established solutions.

The studied start-ups constitute an appropriate research setting. On the one hand, they both represent successful cases in terms of their outcomes: they are both continuously growing, they have a healthy portfolio of clients and projects, and have received external funding and numerous awards. On the other hand, methodologically-wise, they share the same contextual and structural conditions that allow us to proceed with a systematic comparison (Eisenhardt, 1989): they both operate in Europe, have been founded and are taxed in Greece, they operate within the same regulatory system, are influenced and impacted similarly by the ongoing financial crisis and the pandemic-induced financial instability, and they were both established with the backdrop of research and development projects, during which the founders of the start-ups were actively involved.

Our comparative case study is positioned within the interpretive tradition. This allows us to access the multiple actors' viewpoints while considering the local and broader contextual conditions of the organisational environment (Walsham, 2006). We analyse our qualitative material by adopting a subset of Grounded Theory procedures, and specifically, the coding procedures of the constructivist Grounded Theory Method of initial coding, focused coding and theoretical coding (Charmaz, 2006). This approach helps us organise and analyse our empirical material, and develop a rich description of the observed phenomena (Wiesche et al., 2017), i.e., how start-ups make sense of BA for decisionmaking. In addition, adopting the constructivist Grounded Theory subset of procedures permits us to draw from the theory of Sensemaking (Weick et al., 2005), and use it as our sensitising device for 
inductive theorising while, at the same time, remaining open to emerging concepts and themes (Zamani \& Pouloudi, 2020).

\subsection{Data Collection}

We conducted semi-structured interviews with members from the two start-ups and collected additional material from other sources (role descriptors, company reports, publicly available information from the start-ups' websites) for triangulation purposes (Eisenhardt, 1989). Table 1 offers a summary of the interviewees and the gathered interview material. Table 4 and Table 5 provide snapshots of the composition of the two start-ups at the time of our study. Preliminary interviews were conducted between April and May 2020. We conducted follow up interviews during June 2020 with key interviewees to clarify core ideas and confirm our interpretations and the evolving coding scheme. Most of the interviews were recorded (with the informant's permission), and later transcribed. For those interviews, we didn't have recording consent, we kept detailed notes.

Table 1. Breakdown of interview material

\begin{tabular}{|l|l|r|r|r|}
\hline \multicolumn{1}{|c|}{ ID } & \multicolumn{1}{|c|}{ Case } & \multicolumn{1}{c|}{$\begin{array}{c}\text { Word Count (total } \\
\text { number of characters) }\end{array}$} & $\begin{array}{c}\text { Word Count (excluding } \\
\text { words with 3 or } \\
\text { characters) }\end{array}$ \\
\hline John & RetailAnalytics & $57 \mathrm{~min}$ & 7230 & 7001 \\
\hline John & RetailAnalytics & Online chat (follow up) & 622 & 421 \\
\hline Agatha & RetailAnalytics & $1 \mathrm{hr} 7 \mathrm{~min}$ & 8288 & 2074 \\
\hline Agatha & RetailAnalytics & $39 \mathrm{~min}$ (follow up) & 3841 & 237 \\
\hline Agatha & RetailAnalytics & Online chat (follow up) & 340 & 9169 \\
\hline Iris & RetailAnalytics & $1 \mathrm{hr} 12 \mathrm{~min}$ & 9504 & 8807 \\
\hline Lamar & RetailAnalytics & $1 \mathrm{hr} 23 \mathrm{~min}$ & 5970 & 5662 \\
\hline Danny & RetailAnalytics & $49 \mathrm{~min}$ & 4973 & 4825 \\
\hline Evanna & RetailAnalytics & $51 \mathrm{~min}$ & 3799 & 3677 \\
\hline Solomon & SocialAnalytics & $41 \mathrm{~min}$ & 5408 & 5263 \\
\hline Lara & SocialAnalytics & $43 \mathrm{~min}$ & & \\
\hline Lara & SocialAnalytics & $32 \mathrm{~min}$ (follow up) & $57 \mathrm{~min}$ & (Not recorded) \\
\hline Greta & SocialAnalytics & & (Not recorded) \\
\hline
\end{tabular}

\subsection{Data Analysis}

For our analysis, we adopted the constructivist Grounded Theory (GT) procedures for coding, i.e., initial coding, focused coding, and theoretical coding (Charmaz, 2006). Our approach was both inductive and influenced by prior literature and our research question in the spirit of coding following the constructivist GT procedures (Charmaz, 2006). In other words, while there was an open scope for themes emerging directly from the data, we did draw inspiration from existing literature on BA (e.g., Krishnamoorthi \& Mathew, 2018), project selection and prioritisation (e.g., Constantiou et al., 2019), systems development (e.g., Conboy, Mikalef, et al., 2020; Dennehy \& Conboy, 2018) and, especially sensemaking (Weick et al., 2005), which forms the theoretical underpinnings for our study.

Our analysis began with the familiarisation step with the empirical material. This step entailed reading through the transcripts and the additional collected material, comparing what was offered from our informants in relation to the company documents we were provided with and publicly available 
information. While doing so, we were keeping detailed memos with preliminary thoughts. With regards to coding, we began with initial coding, coding our material line-by-line, identifying the main concerns of the informants and cues in our material, using Nvivo codes and keeping coding emergent wherever possible (Charmaz, 2006). We then moved on to focused coding, moving a layer upwards, and identifying codes that seemed to have a more substantial analytical power (Charmaz, 2006). We synthesised open codes into more focused codes, identifying our study's core categories, and memoing became more intensive as we started understanding the processes (Urquhart, 2012) our informants were going through in their sensemaking journey while using BA in their decision making. This process lent itself into the next stage: our focused codes morphed into theoretical ones, i.e., where we built the relationships between the core categories and where we treated Weick's sensemaking stages (noticing and bracketing, labelling and categorising, plausible outcomes and course of action) (Weick et al., 2005) as the major categories in our coding scheme, paying close attention at the interactions between them and the use of BA within each of them. From there, a major theme emerged - the use of business analytics as a sensitising and legitimising device for project selection and prioritisation. Table 2 provides an overview of our data analysis process, whereas Table 3 presents the results of our coding concerning the two case studies.

\section{Table 2. Process of Data Analysis}

\begin{tabular}{|c|c|c|}
\hline Stage & Aim & Method \\
\hline 1. Familiarisation & $\begin{array}{l}\text { Identification of major } \\
\text { themes }\end{array}$ & $\begin{array}{l}\text { Reviewing of the empirical material } \\
\text { Memoing }\end{array}$ \\
\hline 2. Analytical & $\begin{array}{l}\text { Exploration of similarities } \\
\text { and differences: within } \\
\text { and across informants, } \\
\text { within and the two cases. }\end{array}$ & $\begin{array}{l}\text { Initial: line-by-line analysis, coding of interviews around } \\
\text { known and emergent themes (Charmaz, 2006; } \\
\text { Urquhart, 2012). } \\
\text { Focused: Initial codes grouped into larger codes with } \\
\text { stronger analytical power (Charmaz, 2006), inspired by } \\
\text { the Sensemaking Theory. } \\
\text { Theoretical: moving on to a higher level of abstraction, } \\
\text { identifying core categories (Charmaz, 2006; Urquhart, } \\
\text { 2012). }\end{array}$ \\
\hline $\begin{array}{l}\text { 3. Review of the } \\
\text { coding scheme }\end{array}$ & $\begin{array}{l}\text { Ensuring that our coding } \\
\text { scheme reflects the } \\
\text { purpose of the study, and } \\
\text { is exhaustive. }\end{array}$ & $\begin{array}{l}\text { The first two authors reviewed the coding scheme to } \\
\text { avoid overlaps between codes and non-coded material. } \\
\text { They examined the data for data saturation and the } \\
\text { analysis for theoretical saturation, and that it reflected } \\
\text { the topic of research accurately. }\end{array}$ \\
\hline $\begin{array}{l}\text { 4. Analysis and } \\
\text { Interpretation }\end{array}$ & $\begin{array}{l}\text { Identification of major } \\
\text { findings in relation to } \\
\text { Business Analytics and } \\
\text { Sensemaking }\end{array}$ & $\begin{array}{l}\text { Targeted queries to the material to address our } \\
\text { research question and reveal subtle } \\
\text { differences/similarities between the two cases: how are } \\
\text { BA used within the two cases; what do BA help them } \\
\text { achieve; how do the two start-ups make sense } \\
\text { regarding project development, selection and } \\
\text { prioritisation; where do BA fall short. }\end{array}$ \\
\hline 5. Contextualisation & $\begin{array}{l}\text { Theoretical Integration of } \\
\text { our findings within existing } \\
\text { theories and literature }\end{array}$ & $\begin{array}{l}\text { Revisiting of existing literature on BA, project selection } \\
\text { and prioritisation to enrich the existing body of } \\
\text { knowledge based on our findings. }\end{array}$ \\
\hline 6. Reporting & $\begin{array}{l}\text { Development of the chains } \\
\text { of evidence and the } \\
\text { presentation of our } \\
\text { findings }\end{array}$ & $\begin{array}{l}\text { Selection of quotes, construction of reporting tables } \\
\text { (Table 3), developing findings. }\end{array}$ \\
\hline
\end{tabular}


Note: In this table, the process appears sequential, where the analysis is presented following different stages. In reality, the process was highly iterative, especially within the Analytical stage, and contained feedback loops between stages 2-5.

We analysed first the interviews from the RetailAnalytics start-up (case A) and proceeded with a within-case analysis. We then moved on to the SocialAnalytics start-up (case B), conducting a withincase analysis. This allowed us to understand each of the two cases in its own setting first, and to move on with identifying similarities and/or differences on the basis of the evolving coding scheme, concluding with a cross-case analysis (Eisenhardt, 1989). 
Table 3. Core categories, focused codes and initial codes for the two case studies

\begin{tabular}{|c|c|c|c|c|}
\hline Core Categories & Focused codes & Initial codes & $\begin{array}{l}\text { RetailA } \\
\text { nalytics }\end{array}$ & $\begin{array}{c}\text { SocialAn } \\
\text { alytics }\end{array}$ \\
\hline \multirow{11}{*}{$\begin{array}{l}\text { Noticing and } \\
\text { Bracketing }\end{array}$} & \multirow[t]{4}{*}{ using BA } & application areas of BA & $\bullet$ & $\bullet$ \\
\hline & & monitoring & $\bullet$ & $\bullet$ \\
\hline & & tracking & $\bullet$ & $\bullet$ \\
\hline & & BA dashboards & $\bullet$ & $\bullet$ \\
\hline & \multirow[t]{3}{*}{ uncertainties } & reducing uncertainty & $\bullet$ & $\bullet$ \\
\hline & & understanding the market & $\bullet$ & \\
\hline & & pandemic & $\bullet$ & \\
\hline & \multirow[t]{4}{*}{ environmental conditions } & team & $\bullet$ & • \\
\hline & & VC & $\bullet$ & \\
\hline & & consultation with clients & $\bullet$ & $\bullet$ \\
\hline & & GDPR & $\bullet$ & $\bullet$ \\
\hline \multirow{16}{*}{$\begin{array}{l}\text { Labelling and } \\
\text { Categorising }\end{array}$} & \multirow[t]{6}{*}{ organisational values } & provide value to clients & $\bullet$ & $\bullet$ \\
\hline & & push the market and the competition forward & $\bullet$ & \\
\hline & & quality driven /excellence & $\bullet$ & $\bullet$ \\
\hline & & respect for each other and clients & $\bullet$ & $\bullet$ \\
\hline & & using metrics to shape the business & $\bullet$ & $\bullet$ \\
\hline & & personal development & $\bullet$ & $\bullet$ \\
\hline & \multirow[t]{3}{*}{ opportunities } & attracting clients and users & • & $\bullet$ \\
\hline & & user engagement & $\bullet$ & $\bullet$ \\
\hline & & user feedback & $\bullet$ & \\
\hline & \multirow[t]{2}{*}{ past organisational events } & using BA for assessing historical data/past projects & $\bullet$ & $\bullet$ \\
\hline & & comparing with previously developed features & $\bullet$ & \\
\hline & \multirow[t]{2}{*}{ resource allocation } & configuring resources and assets & $\bullet$ & \\
\hline & & using BA for effort estimation & $\bullet$ & $\bullet$ \\
\hline & \multirow[t]{3}{*}{ being informed by BA } & 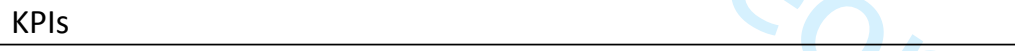 & $\bullet$ & $\bullet$ \\
\hline & & 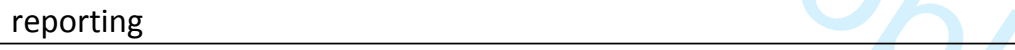 & $\bullet$ & $\bullet$ \\
\hline & & predictive analytics & $\bullet$ & \\
\hline \multirow[t]{3}{*}{ Plausible Outcomes } & \multirow[t]{2}{*}{ risk } & the burden of not having all the data & $\bullet$ & \\
\hline & & data protection and GDPR & $\bullet$ & $\bullet$ \\
\hline & brand management & potential reputation damages & $\bullet$ & \\
\hline
\end{tabular}




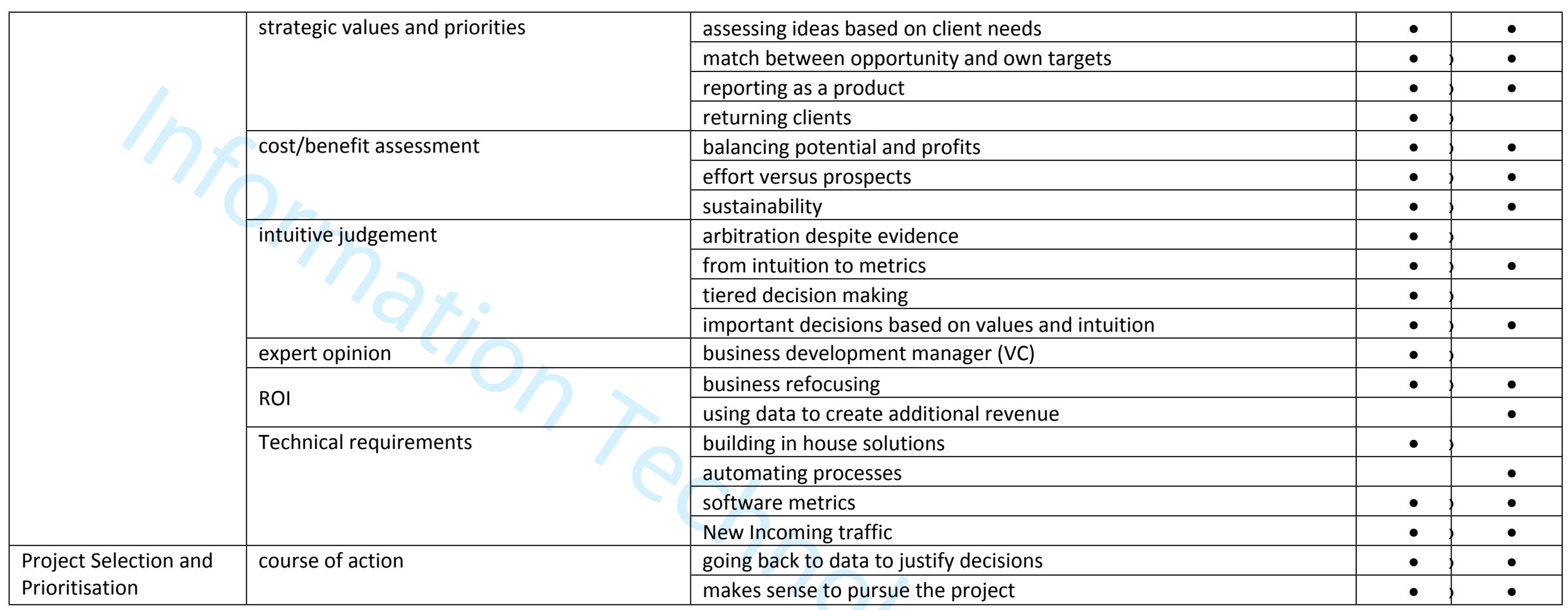




\section{Findings}

Both start-ups use BA internally for monitoring their operations and processes, but also as part of their offering to their clients. At the same time, they exhibit some differences. SocialAnalytics is a somewhat mature company and far ahead in terms of using analytics for the purpose of building products and services, but only recently started becoming a data-driven decision-making business. RetailAnalytics, on the other hand, is a comparatively new start-up and uses BA throughout its operations and processes: from capturing and securing clients and users, to monitoring the competition, tracking project and systems development. In what follows, we report how each start-up uses BA for project selection and prioritisation, offering evidence of the sensemaking stages of noticing and bracketing, labelling and categorising, illustrating the plausible outcomes and then discussing the course of action taken.

\subsection{Start-up A: RetailAnalytics}

RetailAnalytics provides market research and marketing solutions on the basis of location data. It has developed a mobile application used by consumers to receive rewards by brands and retailers as they travel across the city. Their clients are various retailers around Europe, ranging from grocery stores to small cafeterias, and major food suppliers. Currently, RetailAnalytics provides consulting and ad-hoc analytics services and reports. These reports are mostly pre-defined and exploit both descriptive and data mining analytics, including market research results based on specific queries, user segmentation and profiling based on users' most visited areas and stores, areas correlation, footfall reporting etc. At the same time, they generate analytics reports and develop custom features for their mobile application based on client needs. Nine months ago, RetailAnalytics received funding from a Venture Capital (VC) fund, to develop a real-time business analytics platform with predictive capabilities for their B2B (Business to Business) customers.

The RetailAnalytics team comprises of 10 team members (Table 4), whereby three of them are cofounders, four are employees, two are external contractors, and one is the business development manager from the VC side and supports the start-up.

Table 4. Basic Information on RetailAnalytics (Case A) Informants

\begin{tabular}{|l|l|c|c|c|c|}
\hline \multicolumn{1}{|c|}{ ID } & \multicolumn{1}{|c|}{$\begin{array}{c}\text { Years of title } \\
\text { Experience }\end{array}$} & $\begin{array}{c}\text { Months in the } \\
\text { start-up }\end{array}$ & Position & Informant \\
\hline John & CEO and General Director & 10 & 19 & Co-founder & Yes \\
\hline Agatha & Head of BA & 8 & 19 & Co-founder & Yes \\
\hline Lamar & Tech lead & 13 & 19 & Co-founder & Yes \\
\hline Danny & Marketing and Product Manager & 3 & 9 & Employee & Yes \\
\hline Gordon & Data scientist 1 & 13 & 2 & Employee & No \\
\hline Evanna & Data scientist 2 & 1 & 3 & Employee & Yes \\
\hline Jad & Operations manager & 1 & 2 & Employee & No \\
\hline Iris & Business Development Manager & 9 & 9 & VC & Yes \\
\hline Geoffrey & Android developer & 15 & 10 & Contractor & No \\
\hline Arthur & Backend developer & 12 & 5 & Contractor & No \\
\hline
\end{tabular}

The start-up's ultimate goal is to develop Analytics as a Service (AaaS) to serve both retailers and suppliers. The long-term vision is to exploit analytics to the full extent: the team wants to use their 
platform for measuring the success and profitability of each released feature, and they want to use this platform for selecting and prioritising features to be released.

Despite being a data-driven business, John, RetailAnalytics' CEO and General Director is the one who decides on the prioritisation and criticality of new and existing features. To do this, he uses his intuition and estimations on the profitability of similar, previously released, features. While the start-up is often focused on developing features asked for by their existing clientele, they also develop solutions and expand their portfolio of products and services on the basis of market and situational needs. For example, during COVID-19, they expanded their application from being a purely location analytics platform into one with queue monitoring and tracking functionality, coupled with traffic information outside grocery stores. In what follows, we describe the sensemaking process for the prioritisation of this project, and how BA was used for triggering and sensitising the start-up's understanding of the unfolding situation, and ultimately for legitimating their decision-making.

BA functioned as an early warning system, whereby BA-derived insights showed RetailAnalytics that user engagement was falling. Namely, BA indicated that there was less activity on the app and an increasing number of uninstallations, which were coupled with additional insights:

"We use app metrics for everything. We track the screens users visit, which button they tap on, what spots they visit. We measure all these, and we produce reports accordingly" (Danny).

The team realised that what they were seeing on their BA dashboards was in fact an early indication of the future outcomes of the social distancing measures, which would soon be having an impact on the start-up's profitability:

"we had a product that was no longer viable in the current environment. The conditions were different, so we had to motivate our users to log in, using something that was useful at that particular point in time" (John).

Against this backdrop, Agatha came up with an idea:

"I was at the airport, and I was observing the long queues, and I was thinking 'if only they could let me know when the queue is shorter so that I don't have to come in close contact with others' (...) This can happen at the supermarket, we will have the same problems there. It may be a good idea to use the geolocation features of our app and help our clients with queues" (Agatha).

After Agatha communicated her idea to John, the team started looking into Agatha's idea, applying BA on their historical data to predict the viability, success, cost and risks of failure of this new feature against other alternatives (e.g., gamification and Augment Reality features). Initially, they made predictions on the costs (e.g., development costs, other resources required etc.), whereas the success of this new feature was calculated in terms of predicted new clients, publicity, new users, revenues etc. This way they decided in a structured way on whether they will select the development of this feature and prioritise it as critical. Predictions around the time to release were also made based on the past performance of their developers.

"Based on our existing client base, we projected the percentage of clients that are willing to pay to acquire insights derived by this feature, such as: after how many people waiting in the queue the shopper leaves the store, which store they will visit as a second choice, what content, coupons, ads, we can show to them to stay in the current queue" (John).

Apart from using BA to assess the profitability of the new feature, they also looked at how this idea would align with their organisational values. RetailAnalytics emphasises "satisfying user needs and providing value to their clients" (Evanna). "Even when BA indicate a clear roadmap in selecting a new feature or project, if this is against our value, I take the risk to reject it" (John). They thus made sure 
that the new feature was not just an opportunity to maintain or increase their profitability but addressed clients' needs, too.

As the queue monitoring featured started looking better and better, it was time to start predicting the potential consequences of proceeding with its development, including in terms of profitability and overall market positioning. They focused more on gauging expert opinion and basing their decisions on intuitive judgement and less so on leveraging BA:

"The most fundamental thing, in a way, is what the team believes. And maybe, a bit more what our CEO believes, what John believes, in relation to what is happening in the market" (Agatha)

"My intuition is that it was 50-50. We obviously have our metrics, you can't do without them, you consult them, but there is also your intuition, which runs high. Maybe this is my personal opinion. The more metrics you have, and the more you can turn stuff into measurable things, you can base your judgement on data, the more data-driven you are, the less uncertainty you have.

(...) But our prior experience and intuition were core." (Danny)

The team also looked into potential risks and reputation harm. GDPR is always a concern when an application "is based on the interaction with the user, and on storing user location data" (Evanna). "The slightest mistake regarding data handling could impact our GDPR compliance procedures. This can be a problem for the value offered to our clients" (Agatha). "Using past insights from a GDPR-related issue and the reputation harm it caused, we tried to balance the pros and cons [of this new feature] (John). However, the greatest risk was of 'not getting it right':

"I cannot charge a client [for this feature] and send a report with inaccurate insights, what if they monitor their queue in one specific store to assess our feature's accuracy, and we fail?" (John)

These concerns were then assessed against the forecasted return on investment (ROI) and in relation to the start-up's strategic priorities. Danny, who ran the user analysis, mentioned that:

"potential users would have greater value; they have greater customer lifetime value. So, with this lifetime value, we want to bring more users like them, because it is this type of users we want, these users make sense for us" (Danny)

The final aspect they assessed related to the technical requirements of the project, and how that would impact features that were either under development or scheduled to be developed, in order to decide on resource allocation:

"Based on KPIs, what works, what doesn't, where do we need a fast decision to move forward, how many resources do we have committed elsewhere" (John)

"In our company, we have two contractors, so we have to be careful about their development hours, as they cost a lot (... ) I had to predict how much time they will spend on this [feature] based on our prior-released features, and to create a list with other features they had in their development stack, and now they will not develop to cut down costs". (Lamar)

On the aggregate, it was judged that:

"The risk we could forecast was small to hold back, we could launch following a positive approach, and we decided to launch" (Iris) 
Following this decision, RetailAnalytics had to decide what would be their subsequent steps in this direction. The sensemaking process was influenced greatly by the overarching organisational values of the start-up. As such, their course of action entailed that the feature had to be quickly launched so as to help their existing and prospective clientele respond to the fast-changing environmental conditions due to the COVID-19 pandemic, which was affecting small and big retailers. Following the launch, the team turned to BA to evaluate post hoc their decision on the basis of the new data coming in:

"We did it fast-forward and had it as number one priority. We made a very quick build and deployment. We did it, and our BA indicated that it started bringing us cheaper users, too" (John).

\subsection{Start-up B: SocialAnalytics}

SocialAnalytics started its operation in 2014 as a social media and web monitoring platform. They offer data, text and sentiment analytics, and their portfolio includes real-time monitoring and competition tracking. These services are offered via a bespoke platform and incorporate additional services depending on the specific needs of the client. The data used primarily comprise of online data, including social media data and news outlets.

SocialAnalytics has received funding from multiple entrepreneurship and start-up competitions. Their clientele includes major financial institutions, international corporations, consulting companies, and smaller retail businesses. While most of their clients have been with them for a while, their work is typically project-based, which entails increased needs for project management, monitoring and costing. It also means that, despite their best efforts to streamline their processes and offer predefined B2B solutions through their platform, for the most part, their services and reporting is mostly ad hoc, and tailor-made for each project. At the time of our study, the core team of SocialAnalytics included eight people (Table 5), two of whom are co-founders, and the rest are employees.

Table 5. Basic Information on SocialAnalytics (Case A) Informants

\begin{tabular}{|l|l|c|c|c|c|}
\hline \multicolumn{1}{|c|}{ ID } & \multicolumn{1}{|c|}{ Job title } & $\begin{array}{c}\text { Years of } \\
\text { Experience }\end{array}$ & $\begin{array}{c}\text { Months in } \\
\text { the start-up }\end{array}$ & Position & Informant \\
\hline Lara & Managing Director & 10 & 96 & Co-founder & Yes \\
\hline Solomon & Data Scientist 1 & 16 & $\begin{array}{c}48 \text { (4 years } \\
\text { break) }\end{array}$ & Co-founder & Yes \\
\hline Rufus & Lead Software Engineer & 6 & 3 & Employee & No \\
\hline Anne & Business Analyst & 4 & 2 & Employee & No \\
\hline Leo & Front End Engineer & 5 & 2 & Employee & No \\
\hline Casey & Operations \& Presales & 4 & 1 & Employee & No \\
\hline Celeste & Communication \& Reporting & 3 & 2 & Employee & No \\
\hline Greta & Data Scientist 2 & 1 & 5 & Employee & Yes \\
\hline
\end{tabular}

Like John, Lara is the one making all the critical decisions and does so more on the basis of her intuition and prior experience, rather than insights from BA. Recently, she has been noticing that not all projects return adequate profits when controlling for effort, suggesting that there are discrepancies and slippages in how the start-up has been monitoring and controlling their work. She has done this by leveraging their BA solution, which nevertheless is not particularly sophisticated. However, being a data-driven business, Lara believes that they should be doing a better job at using their BA abilities and tools for decision-making and project management. Her long-term goal is to be able to track and 
monitor every single piece of work that goes into a project. Lara believes this will allow them to cost their projects properly, estimate the time spent more accurately and ultimately increase their profitability by offering better insights with regards to their operations. In what follows, we present how BA helped SocialAnalytics identify discrepancies, refocus their business, and ultimately with project selection.

SocialAnalytics originally aimed at offering access to their platform on a subscription basis, and bespoke reporting for specific clients. However, the two co-founders observed that clients were asking considerably more bespoke reports, which was putting the team in a lot of pressure, due to the timesensitive nature of these ad hoc queries. At the time, the two co-founders were hesitant to reject any requests for fear of losing the client altogether:

"At the time, we didn't have the flexibility to be selective with projects. (...) We were making a lot of meetings with prospective clients; we were working a lot, coming up with ideas, making demos and such. But at the end of the day, when you had 50 such meetings, and you don't have anything, you don't have funds, it's resources spent." (Solomon)

However, Lara, having sole responsibility and complete overview of their financial position of the startup, she looked further into the consequences and the major problematic areas:

"I ran an analysis on how much we cost things, how much revenue the platform was making, and how much the platform costs: the data collection, maintaining the server, handling and managing things internally, how much reporting costs, what is more profitable. (...) Using simple $B A$, I realised that the way we were running our projects was just not profitable, the services were not profitable." (Lara)

Using BA, coupled with KPIs, told Lara "what works and what doesn't (...) And BA told us; clearly, we had problems. It told us where the problems were, which projects were problematic, why they had a red flag, and that meant we had to do something". In effect, Lara used BA to bracket her concerns around specific projects against the start-up's targets, making her understanding more focused and streamlined. At the same time, she was guided by SocialAnalytics' organisational values: excellence, mutual respect, personal development, funding and responsibility towards clients, and longer-term targets. Together with Solomon, she leveraged BA to identify ways forward:

"I started looking systematically our NPS (Net Promoter Score), our clients' satisfaction and how valuable they consider SocialAnalytics for their strategy, so that we could understand better what more they would like or need. So, we started doing some research around these using our BA." (Lara)

This has helped them categorise incoming projects as more important than others concerning their objectives, and in relation to their organisational values, it allowed them to increase client engagement:

"From the services side, it could be that I talked to an existing client to see what else could they need, and they wanted this or that, or maybe something in addition to what they already have, like data collection and metrics and then the development of a service that would look like that from the side of the business." (Solomon)

Having "realised that the business is in a difficult position" (Lara), SocialAnalytics had to make changes to their business model, and BA was already indicating the way to go: from a platform-based solution to one that had reporting at its core. As part of sensemaking, the two co-founders sought to evaluate the plausible outcomes should they were to proceed with this move, and chief among their concerns were their strategic priorities, the ROI, any data-related risks, and they conducted a thorough costbenefits assessment: 
Focusing on these software metrics helped the team identify exactly which parts of the business should be automated in order to increase profitability and lower costs:

"I personally see the business processes: how many requests are made by the business team to the dev team on a daily basis. I check Jira and all tickets. If there are many requests, it means there is something that should probably be automated to save us time and money. But this is on the basis of my judgement rather than what BA says" (Lara).

Refocusing the business model entailed also developing mechanisms for selecting prospective projects rather than working on each and every one that came across. The two co-founders shared that for them prospective projects can be classified into three categories: those with direct, tangible profits (financial), those with intangible profits (e.g., reputation benefits, news clients, paid in kind), and those with little/no profit or even losses. Naturally, the team is interested in working on projects of the first two types. They mentioned that BA helps them understand beforehand what kind of a project they have in their hands and make their project selection accordingly. Nevertheless, they also mentioned that the base their final decision on intuitive judgement, prior experience and long-term goals, often irrespective of what BA tells them:

"Being selective is important; we're interested in working on projects that align to some extent with our own long-term targets. (..) We have a client, and we know, based on our metrics, that we are operating at a loss with them. But we did take up the project because the client is very reputable in the market and we wanted to take advantage of this so that more clients from the same industry put their trust on us" (Lara).

\section{Discussion and Contribution}

The aim of this study has been to understand how data-driven start-ups make sense of BA insights for decision making. To do this, we focused on applying a sensemaking lens to understand how two startups select and prioritise projects on the basis of BA insights and showed that BA can be critical for the initial stages of sensemaking for project selection and prioritisation, but that they are less used at the later stages.

Project selection and prioritisation are implicitly influenced by each start-up's strategy and business model. RetailAnalytics' strategy is to build a scalable solution and avoid ad-hoc projects and reporting, show growth to the $V C$ fund and raise a second round of funding; as such, they used simple forms of BA to monitor their performance, and they applied more sophisticated BA on historical data to decide on whether they will select and prioritise a specific queue monitoring feature. Whereas SocialAnalytics' 
strategy is more conservative; rather than being risk-takers, they seek economic viability and positive cashflow; as such they use BA to asses each potential project and prioritise it according to their resources. Unlike John, Lara feels more pressure: because she is the sole responsible for commercial issues. On the other hand, John's team consists of many business people, who are eager to take up new projects, and sometimes with some naivety regarding the effort and the requirements entailed. This is reflected in each company's values. RetailAnalytics' values entail being innovative, and their motto is 'done is better than perfect', whereas SocialAnalytics' values are excellence and quality. This also means that RetailAnalytics is more likely to be influenced by environmental conditions in the noticing and bracketing stage, rather than SocialAnalytics.

SocialAnalytics is more structured than RetailAnalytics on storing and tracking metrics and analytics for project management purposes, and on using agile practices in their development. SocialAnalytics use tools (e.g., Jira) to track bugs, downtimes, requests etc., whereas RetailAnalytics usually store and monitor such metrics in an unstructured and decentralised manner, if and when needed (e.g., via emails, Slack, spreadsheets, analytics platforms). However, even so, RetailAnalytics seems to exploit BA far better than SocialAnalytics, whereby the latter place much greater emphasis on intuition and personal judgement. There are two potential explanations for this: first, BA in RetailAnalytics form part of both their product and processes, i.e., BA are better integrated; second, SocialAnalytics is a more experienced business, and therefore may be more confident in making decisions on the basis of intuition and personal judgement.

The insights derived from BA help the two teams map out the current state of the business, concentrate and explain away the more critical questions with regards to their observations. Namely, BA supports them in identifying the main issues that are meaningful for profitability, growth, development and productivity, and ultimately, from a sensemaking perspective, help them craft a roadmap for arriving in a decision around project selection and prioritisation. While BA can shape and re-shape sensemaking during the decision process regarding project selection and prioritization as new data and insights become continuously available, BA alone cannot do that. Instead, BA is the sensitising device that filters through the critical questions and directs the teams where to look next for further information and insights in order to enrich their understanding and decision making around the business problem. As shown in Table 6, BA is used for the initial stages of noticing and bracketing and labelling and categorising, but when it is time to assess the plausible outcomes of preliminary decisions, both teams base their sensemaking almost exclusively on intuitive judgement, their strategic priorities and values and a cost-benefit assessment, rather than insights from BA. Nevertheless, they do fall back to BA to evaluate their decisions post hoc, as a way to justify their decision-making, drawing legitimacy from the data, and this has been particularly the case with RetailAnalytics, who are still in the process of securing a second round of funding.

Table 6. Overview of findings

\begin{tabular}{|c|c|c|}
\hline & RetailAnalytics & SocialAnalytics \\
\hline $\begin{array}{l}\text { Noticing and } \\
\text { Bracketing }\end{array}$ & $\begin{array}{l}\text { - Environmental Conditions and BA } \\
\text { trigger sensemaking: } \\
\text { o BA as an early warning system } \\
\text { (bracketing what the important } \\
\text { observations): low user } \\
\text { engagement through the app; less } \\
\text { activity; users unregistering }\end{array}$ & $\begin{array}{l}\text { - BA and KPIs triggered sensemaking: } \\
\text { - far more requests (manhours) for } \\
\text { ad hoc reporting; the platform } \\
\text { services were not as profitable; the } \\
\text { business model was not viable. } \\
\text { - BA as an indicator as to where the } \\
\text { start-up needs to focus on being more } \\
\text { profitable (bracketed focus around } \\
\text { problems) }\end{array}$ \\
\hline
\end{tabular}




\begin{tabular}{|c|c|c|}
\hline $\begin{array}{l}\text { Labelling and } \\
\text { Categorising }\end{array}$ & $\begin{array}{l}\text { - Using BA to inform decision-making: } \\
\text { o resource allocation; value to } \\
\text { clients; user engagement; the } \\
\text { potential of a new feature } \\
\text { - Organisational Values count more } \\
\text { than BA insights } \\
\text { - Categorising the potential of the new } \\
\text { feature: an opportunity, a viable } \\
\text { option }\end{array}$ & $\begin{array}{l}\text { - Using BA to highlight problematic } \\
\text { projects: } \\
\text { o Which have a red flag and why. } \\
\text { - Categorising incoming projects: based } \\
\text { on importance with targets and } \\
\text { organisational values }\end{array}$ \\
\hline $\begin{array}{l}\text { Plausible } \\
\text { Outcomes }\end{array}$ & $\begin{array}{l}\text { - Expert opinion/intuitive judgement: } \\
\text { CEO; Business Development Manager } \\
\text { (VC fund) } \\
\text { - Risks: GDPR; reputational damages } \\
\text { (inaccuracies in functionality) } \\
\text { - Costs/Benefits Assessment } \\
\text { (Resources) }\end{array}$ & $\begin{array}{l}\text { - Intuitive judgement (Managing } \\
\text { Director) } \\
\text { - } \text { Strategic Priorities } \\
\text { - } \text { ROI } \\
\text { - } \text { Costs/Benefits Assessment (profit } \\
\text { margin, automating processes using } \\
\text { BA insights) }\end{array}$ \\
\hline Presumption & \multicolumn{2}{|c|}{$\begin{array}{l}\text { Looking at what to do next: BA, i.e., insights from data regarding projected costs and } \\
\text { benefits, estimated needed resources etc. allowed the two start-ups to become aware } \\
\text { of the potential issues and comparatively assess the plausible outcomes. }\end{array}$} \\
\hline $\begin{array}{l}\text { Course of } \\
\text { Action }\end{array}$ & $\begin{array}{l}\text { The project for the Queue Monitoring } \\
\text { Feature was prioritised. } \\
\text { - BA used for reporting on progress to } \\
\text { the VC fund: drawing legitimacy from } \\
\text { the data }\end{array}$ & $\begin{array}{l}\text { The team proceeds with Project Selection } \\
\text { on the basis of BA, but driven by longer- } \\
\text { term strategic priorities: } \\
\text { - BA used for providing some overall } \\
\text { understanding }\end{array}$ \\
\hline $\begin{array}{l}\text { Social and } \\
\text { Systemic }\end{array}$ & \multicolumn{2}{|c|}{$\begin{array}{l}\text { Sensemaking drew from the internal and external contexts of the two start-ups, it was } \\
\text { influenced by environmental conditions (the dynamic and changing competitive } \\
\text { environment), politics and power (the CEO and the Managing Director had greater } \\
\text { influence over decision making, and it was enacted through formal and informal } \\
\text { communications among the two teams through ICTs and face-to-face communications, } \\
\text { during which individuals shared their knowledge and understanding with their teams. }\end{array}$} \\
\hline
\end{tabular}

\subsection{Theoretical Contributions}

What we have explored in this study has the potential to explain some of the open questions existing within the literature of BA. There is a lot of discussion around the value of BA (Brinch et al., 2020; Krishnamoorthi \& Mathew, 2018), and how BA support businesses (Aydiner et al., 2019). Recent studies have focused on illustrating the value of BA quantitatively or identifying the mechanisms of value creation through BA. Wang et al. (2019), for example, discuss that competitive advantage relates to the degree of BA assimilation, which in turn relates to absorptive capacity and BA competency. In turn, Someh et al. (2019) have shown that synergies, i.e., BA-enabled systems, lead to greater value creation rather than when the systems work separately, further strengthening the importance of BA assimilation. However, and while it is unequivocal that BA do offer value and competitive edge, it still less clear how businesses move from insights to actionable decision making when using BA (Seddon et al., 2017).

What our study contributes in this direction is a holistic overview of start-ups' sensemaking process through BA during decision-making for actionable insights, thus responding to recent calls for more research in this front (Mikalef et al., 2020). The analysis shows that BA allows start-ups to observe their environment and promptly make sense of the changes in order to respond by either designing and 
developing new products and services or reshaping and refocusing their business model. Our sensemaking approach shows that BA helps start-ups through their whole development process, from the conceptualization of their new feature, until the assessment of this feature or the project which assists the start-ups in receiving decisions on selection and prioritisation, and later on the monitoring of their actual performance. Apart from the use of BA in project selection, BA in the context of our study also assisted the companies in realising where they are in relation to their competition and whether their position requires adjustment. Overall, using BA the start-ups build their ideas and learn directly from the data, which in effect, makes the data part of the sensemaking roadmap (Asik-Dizdar \& Esen, 2016).

This roadmap is often incomplete and occasionally fragmented, but what is crucial is that it helps startups make targeted use of their BA and organisational capabilities. By applying our sensemaking lens, the analysis shows that $B A$ is used for:

- drawing and focusing attention around critical points, thereby highlighting potential business problems;

- abstracting and carving out the useful information, i.e., distinguishing the useful from the notso-useful-right-now information.

Equally important, however, is that this roadmap is forward-looking. Our study shows that sensemaking may be taking place in the here and now, while building on data from the past and present, but its orientation is future-looking: both start-ups in our case study were enacting their BAenabled sensemaking in order to make decisions with regards to project selection and prioritisation, i.e., for projects to be developed and implemented in the future. Along these lines, we contribute to the sensemaking literature which is characterised by conflicting perspectives regarding the temporal nature of sensemaking, i.e., when sensemaking takes place and whether it is retrospective or prospective (Maitlis \& Christianson, 2014). For example, some scholars argue that sensemaking is forward-looking, thus prospective (e.g., Gephart et al., 2010; Stigliani \& Ravasi, 2012), whereas others posit that it combines elements that are both retrospective and prospective (e.g., Konlechner et al., 2019), e.g., making sense of the past in order to make decisions for the future. We posit that BAenabled sensemaking supports the development of mental representations of how the future might look like based on data collected from the past and the present, thus transcending the temporal boundaries between past, present and future.

On a higher level of abstraction, we extend current knowledge and showcase that BA support startups develop mental representations of the unstructured problems they face; as shown, a start-up can use BA insights to think through the collateral consequences of the alternative scenarios, which facilitates crafting solutions and strategies for addressing unstructured problems, of which project selection and prioritisation are only examples. While this approach of learning-by-thinking has been criticised for delaying the launching of innovation endeavours, especially when compared to the lean start up method or learning-by-doing (Leatherbee \& Katila, 2020), our findings show otherwise. Drawing from BA to play out the alternative scenarios for critical choices around project selection and prioritisation reduces the risks for start-ups, especially when the environmental conditions may pose an existential threat to the business sustainability and the scarcity of resources do not allow learning from mistakes. Along these lines, our findings are compatible with other approaches, such as the resource-based view and the dynamic capability theory, which are often adopted by BA-focused studies (e.g., Conboy, Mikalef, et al., 2020; S. Wang et al., 2019): BA helps start-ups create, combine and recombine their resources into new ones and pivot their products so as to achieve their competitive edge, specifically while they are enacting their sensemaking with the support of BA.

Our third contribution lies with our exploration into the role of intuitive judgement and the aspect of the human factor in BA-driven decision-making. Several studies have called for decision-making to be based on $\mathrm{BA}$ and rationale processes for the purpose of leading to better results compared to intuitive 
judgement (e.g., Dhami \& Thomson, 2012; Z. Wang et al., 2020). However, as others discuss (Fosso Wamba et al., 2017; Mikalef et al., 2020), many studies simply assume that there is a direct relationship between the use of BA and performance gains, without taking the human factor into account. For this relationship to exist, and for decision-making to be indeed superior, one needs to be able to understand and interpret the implications of BA insights and BA-driven decisions (Janssen et al., 2017). We thus contribute by providing a sensemaking approach to BA-driven decision making, extending current thinking into how start-ups use BA for moving from data to actionable insights to decisionmaking. We show that BA alone cannot lead to decisions. Those burdened with high-level decisionmaking tend to prefer their own judgement and draw from their prior experiences informed by the data, but not exclusively on the basis of the data -this is not an entirely new finding. Constantiou et al. (2019) discuss that when decision-makers hold an opinion which is at odds with the results from a Business Intelligence (BI) system, they often revert to making their decision on the basis of their intuitive judgement rather than on what the BI system tells them. While we did not find evidence of the decision-makers disagreeing with the BA insights, we echo Constantiou et al. (2019)'s view and offer an alternative explanation for our own findings. We posit that in the case of our two start-ups intuitive judgement is mobilised in order to align decision-making with their organisational values and the strategic priorities, neither of which can be captured by the BA tools and thus inform the output. In other words, we consider that while making sense of the BA outputs, and considering the plausible outcomes of their decision-making, the values and priorities of the start-ups' function as the guiding principle for go/no-go decisions with regards to project selection and prioritisation. It is their values and priorities that make up their sense of self and it is their choices with regards to which projects they will work on that make up the identity of the start-up. Therefore, choices have to be consistent with the organisational values and priorities, which is an area where BA cannot perform as well as one's experience and judgement.

A fourth contribution stems from the use of Sensemaking theory as the theoretical lens of our study. Sensemaking in general, while interested in how individuals and organisations make sense of phenomena and proceed in their decision-making, places greater emphasis on the actions that precede decision-making, because it is these actions that shape the form of the decision (Glynn \& Watkiss, 2020; Weick \& Sutcliffe, 2015). However, in "[m]ost technology sensemaking inquiries (...) [a]ctions are seen as the product of sensemaking rather than as an antecedent." (Mesgari \& Okoli, 2019, p. 217). In our study, we have clearly illustrated how the members of the two start-ups collectively make sense and enact their sensemaking for the purpose of making decisions and on the basis of their BA insights. We did so by unpacking the moments in their sensemaking, and further elaborating on the environmental conditions and circumstances that influenced them.

\subsection{Practical Implications}

Our study has important practical implications. Start-ups are often faced with unstructured problems, whereby BA tools and methods can help navigate the business problem, ranging from developing new services and pivoting products, to refocusing and reshaping the business model to address changes in the environment. However, they cannot lead to unequivocal decisions. It is likely that this is the case for both small and large business settings. Our study shows that BA tools can be useful for observing one's environment proactively, but also quite useful when used reactively for identifying the origins of business problems and scoping for potential solutions and corrective actions. More importantly, we show that BA tools can be crucial for both project selection and prioritisation because they allow focusing sensemaking around the more probable scenarios. We also note that the importance of intuitive judgement should not be understated. Part of making decisions involves taking stock of unstructured and qualitative information that cannot be captured in BA tools or be assessed by such methods. In this sense, one should be cautious when using BA for such type of decision-making. 
Selecting and prioritising projects is a critical task in start-ups. Many young entrepreneurs struggle between selecting projects that are profitable and support cashflow, and projects that are important for their long-term strategy. BA can play a significant role in easing start-uppers with such decisions. Analytics can be utilised not only as leverage to convince teams and support leaders in decision making (e.g., SocialAnalytics case) but also as a tool to prove to investors and shareholders that the strategy is anchored to data and thus less risky (e.g., RetailAnalytics case). However, occasionally, start-ups are not aware of the value of BA in aiding them in such decisions. Most of the times, start-uppers (and in particular those who work in analytics companies), use BA to offer sophisticated B2B analytical services but neglect the value of analytics in shaping internal decision-making. "Sometimes we use best practices for our clients but don't apply them in our team" is a phrase many of our informants mentioned. Here, the role of the start-up ecosystem is crucial. Incubation centres, acceleration centres and VC funds can draw insights from our study and support their start-ups in exploiting BA for project selection and prioritisation.

\section{Conclusions}

In this study, we have focused on understanding how start-ups make sense of BA for project selection and prioritisation. We have shown that BA can be crucial in both regards but are coupled with intuitive judgement when it is time to evaluate the plausible outcomes of decision making.

Our study comes with some limitations and interesting potential avenues for future research. Both of our cases derive from the Greek start-up scene with a clientele base primarily from the EU. Therefore, our findings should be interpreted with caution when extrapolating outside these geographical boundaries. In the future, it would be interesting to expand this research to study how the sensemaking process with regards to BA differs or resembles that of start-ups and conduct a comparative study SMEs and larger companies. The informants, in various points of the interviews, implied that the way their clients make sense of the BA services they offer significantly affects their strategy. Thus, future research may use sensemaking and focus on the similarities and discrepancies between clients' and start-uppers' sensemaking regarding the value of BA. In the context of this study we mainly focused on how start-ups make sense of BA collectively. Future research may also focus on how the different members of a start-up make sense of BA, and how their background, role in the company and prior experiences influence how they enact their sensemaking.

Another limitation stems from our study's methodological choices. We designed this study as a comparative case study, which we combined with GT procedures. While this approach help us address our research question, and offer a rich description, it does limit the potential of GT (Wiesche et al., 2017). We would thus propose that future research explores the potential of expanding the use of GT (e.g., incorporate theoretical sampling), in order to extend our findings to theory, and then validate these across different contexts (Urquhart, 2016).

\section{References}

Arar, Ö. F., \& Ayan, K. (2016). Deriving thresholds of software metrics to predict faults on open source software: Replicated case studies. Expert Systems with Applications, 61, 106-121. https://doi.org/10.1016/j.eswa.2016.05.018

Asik-Dizdar, O., \& Esen, A. (2016). Sensemaking at work: Meaningful work experience for individuals and organizations. International Journal of Organizational Analysis, 24(1), 2-17. https://doi.org/10.1108/IJOA-12-2013-0728

Augustine, V., Hudepohl, J., Marcinczak, P., \& Snipes, W. (2018). Deploying Software Team Analytics in a Multinational Organization. IEEE Software, 35(1), 72-76.

https://doi.org/10.1109/MS.2017.4541044 
Aydiner, A. S., Tatoglu, E., Bayraktar, E., Zaim, S., \& Delen, D. (2019). Business analytics and firm performance: The mediating role of business process performance. Journal of Business Research, 96, 228-237. https://doi.org/10.1016/j.jbusres.2018.11.028

Behl, A., Dutta, P., Lessmann, S., Dwivedi, Y. K., \& Kar, S. (2019). A conceptual framework for the adoption of big data analytics by e-commerce startups: A case-based approach. Information Systems and E-Business Management, 17(2-4), 285-318. https://doi.org/10.1007/s10257-01900452-5

Brinch, M., Gunasekaran, A., \& Fosso Wamba, S. (2020). Firm-level capabilities towards big data value creation. Journal of Business Research, S0148296320304859. https://doi.org/10.1016/j.jbusres.2020.07.036

Charmaz, K. (2006). Constructing Grounded Theory. A Practical Guide through Qualitative Analysis. SAGE Publications.

Chen, Chiang, \& Storey. (2012). Business Intelligence and Analytics: From Big Data to Big Impact. MIS Quarterly, 36(4), 1165. https://doi.org/10.2307/41703503

Conboy, K., Dennehy, D., \& O'Connor, M. (2020). 'Big time': An examination of temporal complexity and business value in analytics. Information \& Management, 57(1), 103077. https://doi.org/10.1016/j.im.2018.05.010

Conboy, K., Mikalef, P., Dennehy, D., \& Krogstie, J. (2020). Using business analytics to enhance dynamic capabilities in operations research: A case analysis and research agenda. European Journal of Operational Research, 281(3), 656-672. https://doi.org/10.1016/j.ejor.2019.06.051

Constantiou, I., \& Kallinikos, J. (2015). New Games, New Rules: Big Data and the Changing Context of Strategy. Journal of Information Technology, 30(1), 44-57. https://doi.org/10.1057/jit.2014.17

Constantiou, I., Shollo, A., \& Vendelø, M. T. (2016). Making Space for Intuition in Decision-Making: The Case of Project Prioritization. In K. J. Sund, R. J. Galavan, \& A. Sigismund Huff (Eds.), New Horizons in Managerial and Organizational Cognition (pp. 147-169). Emerald Group Publishing Limited. https://doi.org/10.1108/S2397-52102016014

Constantiou, I., Shollo, A., \& Vendel $\varnothing$, M. T. (2019). Mobilizing intuitive judgement during organizational decision making: When business intelligence is not the only thing that matters. Decision Support Systems, 121, 51-61. https://doi.org/10.1016/j.dss.2019.04.004

Daniel, E. M., Ward, J. M., \& Franken, A. (2014). A dynamic capabilities perspective of IS project portfolio management. The Journal of Strategic Information Systems, 23(2), 95-111. https://doi.org/10.1016/j.jsis.2014.03.001

Dennehy, D., \& Conboy, K. (2018). Identifying Challenges and a Research Agenda for Flow in Software Project Management. Project Management Journal, 49(6), 103-118. https://doi.org/10.1177/8756972818800559

Dervin, B. (2003). Chaos, order, and Sense-Making: A proposed theory for information design. In B. Dervin, L. Foreman-Wernet, \& E. Lauterbach (Eds.), Sense-Making Methodology reader: Selected writings of Brenda Dervin (pp. 325-340). Hampton Press.

Dhami, M. K., \& Thomson, M. E. (2012). On the relevance of Cognitive Continuum Theory and quasirationality for understanding management judgment and decision making. European Management Journal, 30(4), 316-326. https://doi.org/10.1016/j.emj.2012.02.002

Dong, J. Q., \& Yang, C.-H. (2020). Business value of big data analytics: A systems-theoretic approach and empirical test. Information \& Management, 57(1), 103124. https://doi.org/10.1016/j.im.2018.11.001

Eisenhardt, K. M. (1989). Building Theories from Case Study Research. Academy of Management Review, 14(4), 532-550.

Fosso Wamba, S., Akter, S., Edwards, A., Chopin, G., \& Gnanzou, D. (2015). How 'big data' can make big impact: Findings from a systematic review and a longitudinal case study. International Journal of Production Economics, 165, 234-246. https://doi.org/10.1016/j.ijpe.2014.12.031 
Fosso Wamba, S., Gunasekaran, A., Akter, S., Ren, S. J., Dubey, R., \& Childe, S. J. (2017). Big data analytics and firm performance: Effects of dynamic capabilities. Journal of Business Research, 70, 356-365. https://doi.org/10.1016/j.jbusres.2016.08.009

Gartner. (2018). Predicts 2019: Analytics and BI Strategy (ID G00372971). Gartner.

Gephart, R. P., Topal, C., \& Zhan, Z. (2010). Future-oriented sensemaking: Temporalities and institutional legitimation. In T. Hernes \& S. Maitlis (Eds.), Process, Sensemaking, and Organizing (pp. 275-312). Oxford University Press.

Giannakis, M., Dubey, R., Yan, S., Spanaki, K., \& Papadopoulos, T. (2020). Social media and sensemaking patterns in new product development: Demystifying the customer sentiment. Annals of Operations Research. https://doi.org/10.1007/s10479-020-03775-6

Glynn, M. A., \& Watkiss, L. (2020). Of Organizing and Sensemaking: From Action to Meaning and Back Again in a Half-Century of Weick's Theorizing. Journal of Management Studies, joms.12613. https://doi.org/10.1111/joms.12613

Griva, A., Bardaki, C., Pramatari, K., \& Doukidis, G. (2021). Factors Affecting Customer Analytics: Evidence from Three Retail Cases. Information Systems Frontiers. https://doi.org/10.1007/s10796020-10098-1

Griva, A., Bardaki, C., Pramatari, K., \& Papakiriakopoulos, D. (2018). Retail business analytics: Customer visit segmentation using market basket data. Expert Systems with Applications, 100, 116. https://doi.org/10.1016/j.eswa.2018.01.029

Griva, A., Byrne, S., Dennehy, D., \& Conboy, K. (2020). Software Requirements Quality: Using Analytics to Challenge Assumptions at Intel. IEEE Software, 0-0. https://doi.org/10.1109/MS.2020.3043868

Gunasekaran, A., Yusuf, Y. Y., Adeleye, E. O., \& Papadopoulos, T. (2018). Agile manufacturing practices: The role of big data and business analytics with multiple case studies. International Journal of Production Research, 56(1-2), 385-397. https://doi.org/10.1080/00207543.2017.1395488

Hilbig, R., Etsiwah, B., \& Hecht, S. (2018). Start-ups - The Rise of Data-Driven Business Models. ISPIM Innovation Symposium, Berlin.

Holsapple, C., Lee-Post, A., \& Pakath, R. (2014). A unified foundation for business analytics. Decision Support Systems, 64, 130-141. https://doi.org/10.1016/j.dss.2014.05.013

Janssen, M., van der Voort, H., \& Wahyudi, A. (2017). Factors influencing big data decision-making quality. Journal of Business Research, 70, 338-345. https://doi.org/10.1016/j.jbusres.2016.08.007

Klein, G., Phillips, J. K., Rall, E. L., \& Peluso, D. A. (2007). A Data/Frame Theory of Sensemaking (R. R. Hoffman, Ed.; pp. 113-155). Lawrence Erlbaum Associates, Taylor \& Francis Group.

Konlechner, S., Latzke, M., Güttel, W. H., \& Höfferer, E. (2019). Prospective sensemaking, frames and planned change interventions: A comparison of change trajectories in two hospital units. Human Relations, 72(4), 706-732. https://doi.org/10.1177/0018726718773157

Krishnamoorthi, S., \& Mathew, S. K. (2018). Business analytics and business value: A comparative case study. Information \& Management, 55(5), 643-666. https://doi.org/10.1016/j.im.2018.01.005

Leatherbee, M., \& Katila, R. (2020). The lean startup method: Early-stage teams and hypothesis-based probing of business ideas. Strategic Entrepreneurship Journal, 14(4), 570-593. https://doi.org/10.1002/sej.1373

Maitlis, S., \& Christianson, M. (2014). Sensemaking in Organizations: Taking Stock and Moving Forward. Academy of Management Annals, 8(1), 57-125. https://doi.org/10.5465/19416520.2014.873177

Malakis, S., \& Kontogiannis, T. (2013). A sensemaking perspective on framing the mental picture of air traffic controllers. Applied Ergonomics, 44(2), 327-339. 
Mäntymäki, M., Hyrynsalmi, S., \& Koskenvoima, A. (2020a). How Do Small and Medium-Sized Game Companies Use Analytics? An Attention-Based View of Game Analytics. Information Systems Frontiers, 22(5), 1163-1178. https://doi.org/10.1007/s10796-019-09913-1

Mäntymäki, M., Hyrynsalmi, S., \& Koskenvoima, A. (2020b). How Do Small and Medium-Sized Game Companies Use Analytics? An Attention-Based View of Game Analytics. Information Systems Frontiers, 22(5), 1163-1178. https://doi.org/10.1007/s10796-019-09913-1

Manyika, J., Chui, M., Brown, B., Bughin, J., Dobbs, R., Roxburgh, C., \& Hung Byers, A. (2011). Big data: The next frontier for innovation, competition, and productivity / McKinsey. McKinsey. https://www.mckinsey.com/business-functions/mckinsey-digital/our-insights/big-data-the-nextfrontier-for-innovation\#

Mayer-Schönberger, V., \& Cukier, K. (2013). Big Data: A Revolution that Will Transform how We Live, Work, and Think. Houghton Mifflin Harcourt.

Mesgari, M., \& Okoli, C. (2019). Critical review of organisation-technology sensemaking: Towards technology materiality, discovery, and action. European Journal of Information Systems, 28(2), 205-232. https://doi.org/10.1080/0960085X.2018.1524420

Meskendahl, S. (2010). The influence of business strategy on project portfolio management and its success-A conceptual framework. International Journal of Project Management, 28(8), 807-817. https://doi.org/10.1016/j.ijproman.2010.06.007

Mikalef, P., Pappas, I. O., Krogstie, J., \& Giannakos, M. (2018). Big data analytics capabilities: A systematic literature review and research agenda. Information Systems and E-Business Management, 16(3), 547-578. https://doi.org/10.1007/s10257-017-0362-y

Mikalef, P., Pappas, I. O., Krogstie, J., \& Pavlou, P. A. (2020). Big data and business analytics: A research agenda for realizing business value. Information \& Management, 57(1), 103237. https://doi.org/10.1016/j.im.2019.103237

Namvar, M., \& Cybulski, J. (2014). BI-based Organizations: A Sensemaking Perspective. International Conference Information Systems (ICIS 2014). International Conference Information Systems (ICIS 2014), Auckland, New Zealand. https://aisel.aisnet.org/icis2014/proceedings/ISStrategy/39/

Pappas, I. O., Mikalef, P., Giannakos, M. N., Krogstie, J., \& Lekakos, G. (2018). Big data and business analytics ecosystems: Paving the way towards digital transformation and sustainable societies. Information Systems and E-Business Management, 16(3), 479-491. https://doi.org/10.1007/s10257-018-0377-z

Pun, K. F., Chin, K. S., \& Yiu, M. Y. R. (2010). An AHP approach to assess new product development performance: An exploratory study. International Journal of Management Science and Engineering Management, 5(3), 210-218. https://doi.org/10.1080/17509653.2010.10671110

Reddivari, S., Rad, S., Bhowmik, T., Cain, N., \& Niu, N. (2014). Visual requirements analytics: A framework and case study. Requirements Engineering, 19(3), 257-279. https://doi.org/10.1007/s00766-013-0194-3

Rodrigues, C. M., Deschamps, F., de Freitas Rocha Loures, E., Cestari, J. M. A. P., \& de Freitas, I. H. (2020). Digital Transformation Project Portfolio Selection/Prioritization: Literature Review and Future Directions. In Z. Anisic, B. Lalic, \& D. Gracanin (Eds.), Proceedings on 25th International Joint Conference on Industrial Engineering and Operations Management - IJCIEOM (pp. 282-292). Springer International Publishing. https://doi.org/10.1007/978-3-030-43616-2_30

Savolainen, R. (1993). The sense-making theory: Reviewing the interests of a user-centered approach to information seeking and use. Informorion Processing \& Management, 29(1), 13-28.

Seddon, P. B., Constantinidis, D., Tamm, T., \& Dod, H. (2017). How does business analytics contribute to business value?: How does analytics contribute to business value? Information Systems Journal, 27(3), 237-269. https://doi.org/10.1111/isj.12101

Seidel, S., Chandra Kruse, L., Székely, N., Gau, M., \& Stieger, D. (2017). Design principles for sensemaking support systems in environmental sustainability transformations. European Journal of Information Systems, 27(2), 221-247. https://doi.org/10.1057/s41303-017-0039-0 
Sharma, R., Mithas, S., \& Kankanhalli, A. (2014). Transforming decision-making processes: A research agenda for understanding the impact of business analytics on organisations. European Journal of Information Systems, 23(4), 433-441. https://doi.org/10.1057/ejis.2014.17

Shollo, A., Constantiou, I., \& Kreiner, K. (2015). The interplay between evidence and judgment in the IT project prioritization process. The Journal of Strategic Information Systems, 24(3), 171-188. https://doi.org/10.1016/j.jsis.2015.06.001

Someh, I., Shanks, G., \& Davern, M. (2019). Reconceptualizing synergy to explain the value of business analytics systems. Journal of Information Technology, 34(4), 371-391. https://doi.org/10.1177/0268396218816210

Stigliani, I., \& Ravasi, D. (2012). Organizing Thoughts and Connecting Brains: Material Practices and the Transition from Individual to Group-Level Prospective Sensemaking. Academy of Management Journal, 55(5), 1232-1259. https://doi.org/10.5465/amj.2010.0890

Tavana, M., Khalili-Damghani, K., \& Abtahi, A.-R. (2013). A hybrid fuzzy group decision support framework for advanced-technology prioritization at NASA. Expert Systems with Applications, 40(2), 480-491. https://doi.org/10.1016/j.eswa.2012.07.040

Urquhart, C. (2012). Grounded Theory for Qualitative Research. A Practical Guide. SAGE Publications Ltd.

Urquhart, C. (2016). Response to Davison and Martinsons: Context is King! Yes and no - it's still all about Theory (Building). Journal of Information Technology, 31(3), 254-256. https://doi.org/10.1057/s41265-016-0002-x

Walsham, G. (2006). Doing interpretive research. European Journal of Information Systems, 15, 320330.

Wang, S., Yeoh, W., Richards, G., Wong, S. F., \& Chang, Y. (2019). Harnessing business analytics value through organizational absorptive capacity. Information \& Management, 56(7), 103152. https://doi.org/10.1016/j.im.2019.02.007

Wang, Z., Wang, N., Su, X., \& Ge, S. (2020). An empirical study on business analytics affordances enhancing the management of cloud computing data security. International Journal of Information Management, 50, 387-394. https://doi.org/10.1016/j.ijinfomgt.2019.09.002

Weick, K. E., \& Sutcliffe, K. M. (2015). Managing the Unexpected: Sustained Performance in a Complex World. John Wiley \& Sons.

Weick, K. E., Sutcliffe, K. M., \& Obstfeld, D. (2005). Organizing and the Process of Sensemaking. Organization Science, 16(4), 409-421.

Wiesche, M., Jurisch, M. C., Yetton, P. W., \& Krcmar, H. (2017). Grounded Theory Methodology in Information Systems Research. MIS Quarterly, 41(3), 685-701.

Zamani, E. D., \& Pouloudi, N. (2020). Generative mechanisms of workarounds, discontinuance and reframing: A study of negative disconfirmation with consumerised IT. Information Systems Journal, 31(4), 1-45. https://doi.org/10.1111/isj.12315

Zamani, E. D., Pouloudi, N., Giaglis, G., \& Wareham, J. (2019). Accommodating Practices During Episodes of Disillusionment with Mobile IT. Information Systems Frontiers. https://doi.org/10.1007/s10796-019-09972-4

Zhang, D., Han, S., Dang, Y., Lou, J.-G., Zhang, H., \& Xie, T. (2013). Software Analytics in Practice. IEEE Software, 30(5), 30-37. https://doi.org/10.1109/MS.2013.94 